\section{Commentary: Engineering antibody therapies may be the future of therapeutics}

\author{
Akbarshakh Akhmerov, MD, and \\ Danny Ramzy, MD, PhD
}

CRISPR (clustered regularly interspaced short palindromic repeats)-Cas9 (CRISPR-associated protein 9) technology has revolutionized the field of genome editing. This molecular technique initially emerged from basic research into the mechanisms of prokaryotic immunity but has since been adapted within eukaryotic systems for therapeutic purposes. ${ }^{1}$ The CRISPR-Cas9 complex involves: (1) an endonuclease (Cas9), capable of making a double-stranded DNA break; and (2) a short guide RNA, which directs the complex to specific sites within the genome. During repair of the double-stranded break, a specific DNA template can be introduced, thereby enabling gene insertion. Although this is not the first method for genome editing, it is simpler, more efficient, and more flexible than its predecessors. ${ }^{2}$ In the context of adaptive immunity, CRISPR-Cas 9 can be harnessed to engineer B cells with tailored, antiviral properties.

In the current issue of Journal, Lam and Farber $^{3}$ describe how B cells can be engineered with CRISPR-Cas9 editing to produce specific antibodies against the respiratory syncytial virus, as well as other viruses. Transferring these engineered B cells into immunocompromised mice conferred protection against respiratory syncytial virus infection up to 87 days. ${ }^{4}$ The authors contrast this novel approach with other available therapies, including monoclonal antibodies (eg, palivizumab) and viral transduction. As the authors correctly point out, both have limitations: monoclonal antibodies require repeat infusions and are costly, whereas virally transduced

From the Department of Cardiac Surgery, Smidt Heart Institute, Cedars-Sinai Medical Center, Los Angeles, Calif.

Funding: Dr Akhmerov was funded by National Institutes of Health grant T32HL116273-07 (Training in Advanced Heart Disease Research).

Disclosures: The authors reported no conflicts of interest.

The Journal policy requires editors and reviewers to disclose conflicts of interest and to decline handling or reviewing manuscripts for which they may have a conflict of interest. The editors and reviewers of this article have no conflicts of interest

Received for publication June 1, 2020; revisions received June 1, 2020; accepted for publication June 2, 2020; available ahead of print June 27, 2020.

Address for reprints: Danny Ramzy, MD, PhD, Department of Cardiac Surgery, Smidt Heart Institute, Cedars-Sinai Medical Center, 127 S. San Vicente Blvd, Suite A3105, Los Angeles, CA 90048 (E-mail: danny.ramzy@cshs.org).

J Thorac Cardiovasc Surg 2021;161:1362-3

$0022-5223 / \$ 36.00$

Copyright (c) 2020 by The American Association for Thoracic Surgery

https://doi.org/10.1016/j.jtcvs.2020.06.041
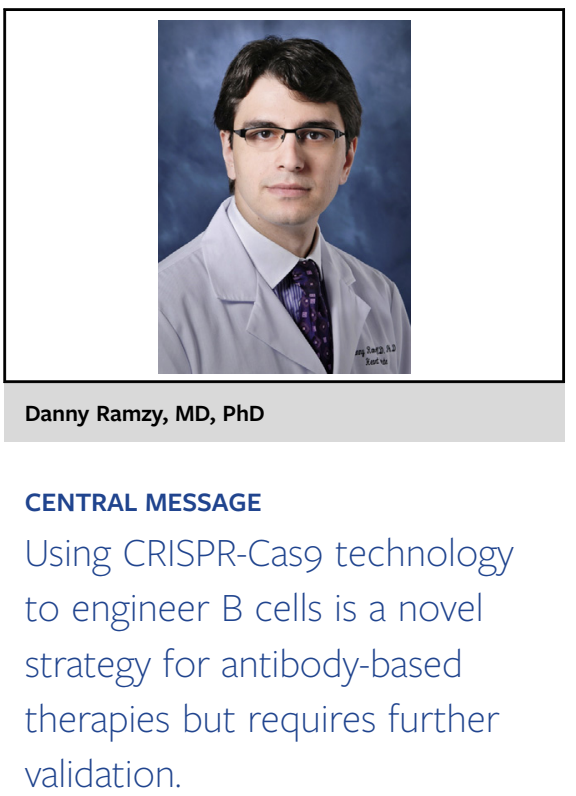

B cells produce fixed levels of antibodies, unresponsive to infection. Thus, CRISPR-engineered B cells have potential advantages over these more traditional approaches.

The authors speculate that this novel strategy may be useful, either prophylactically or therapeutically, in coronavirus disease 2019 (COVID-19), myocarditis, and immunocompromised patients. Although the application is certainly feasible for immunocompromised patients, including transplant recipients, its application in COVID-19 and myocarditis may be limited. Similar to convalescent plasma, engineered B cells are likely to be most effective early in COVID-19 pathogenesis. ${ }^{5}$ With the current 2- to 3-week production time, however, early delivery of engineered B cells will be challenging. Furthermore, although myocarditis is certainly possible with the severe acute respiratory syndrome coronavirus 2 infection, detection of the viral genome within the heart has been exceedingly rare, raising questions about the incidence of genuine myocarditis in COVID-19. ${ }^{5}$ Moreover, in the majority of patients with lymphocytic myocarditis (non-COVID-19), the disease is either clinically silent and/or self-limited with supportive care.

Technical barriers must also be considered. Engineering autologous cells is timely and costly. The use of allogeneic cells from unrelated donors, in contrast, requires immunosuppression. In addition, long-term cryopreservation may alter the cells. ${ }^{6}$ Coupled with potential off-target effects of CRISPR-Cas9 editing, the character of the cells can change significantly during production and storage. Lastly, engineered $B$ cells have not yet been shown to exhibit a modulated response in vivo. After transferring engineered $\mathrm{B}$ cells into mice, the serum antibody levels, the number 
of antibody-secreting plasma cells, and the number of isotype-switched memory B cells were indistinguishable between infected mice and their uninfected counterparts. ${ }^{4}$ Therefore, the unintended consequences of this nonmodulated antibody production must be taken into account.

Despite these potential limitations and uncertainties, however, Lam and Farber review a technology that has immense potential for the development of antibody-based therapeutics.

\section{References}

1. Doudna JA. The promise and challenge of therapeutic genome editing. Nature 2020;578:229-36

2. Adli M. The CRISPR tool kit for genome editing and beyond. Nat Commun. 2018 9:1911.

3. Lam N, Farber DL. Engineering antibody therapies for protective immunity. $J$ Thorac Cardiovasc Surg. 2021:161:1358-61.

4. Moffett HF, Harms CK, Fitzpatrick KS, Tooley MR, Boonyaratanakornkit J Taylor JJ. B cells engineered to express pathogen-specific antibodies protect against infection. Sci Immunol. 2019;4:eaax0644.

5. Akhmerov A, Marban E. COVID-19 and the heart. Circ Res. 2020;126:1443-55.

6. Marban E. A mechanistic roadmap for the clinical application of cardiac cell therapies. Nat Biomed Eng. 2018;2:353-61.
See Article page 1358.

\section{Commentary: Providing optimal care for cardiothoracic patients of the future requires expertise spanning barriers of time and specialization}

\author{
Mara B. Antonoff, MD
}

In this Invited Expert Opinion, Drs Lam and Farber discuss a genetic engineering strategy featuring CRISPR/Cas9 to promote B-cell expression of monoclonal antibodies against viruses - a timely and highly relevant topic as we strive to emerge from this worldwide viral pandemic. ${ }^{1}$ It is also highly relevant to the cardiothoracic surgical community with regard to heart and lung transplantation recipients-individuals who are immunosuppressed and at risk of severe complicating viral illnesses. Although such topics may feel overwhelming to those clinicians or researchers who lack exposure to the basic science laboratory, the

\footnotetext{
From The University of Texas MD Anderson Cancer Center, Houston, Tex. Disclosure: The author reported no conflicts of interest.

The Journal policy requires editors and reviewers to disclose conflicts of interest and to decline handling or reviewing manuscripts for which they may have a conflict of interest. The editors and reviewers of this article have no conflicts of interest.

Received for publication June 9, 2020; accepted for publication June 10, 2020; available ahead of print June 29, 2020.

Address for reprints: Mara B. Antonoff, MD, Department of Thoracic and Cardiovascular Surgery, University of Texas MD Anderson Cancer Center, 1515 Holcombe Blvd, Houston, TX 77030 (E-mail: MBAntonoff@mdanderson.org).

J Thorac Cardiovasc Surg 2021;161:1363-4

$0022-5223 / \$ 36.00$

Copyright (c) 2020 by The American Association for Thoracic Surgery

https://doi.org/10.1016/j.jtcvs.2020.06.073
}

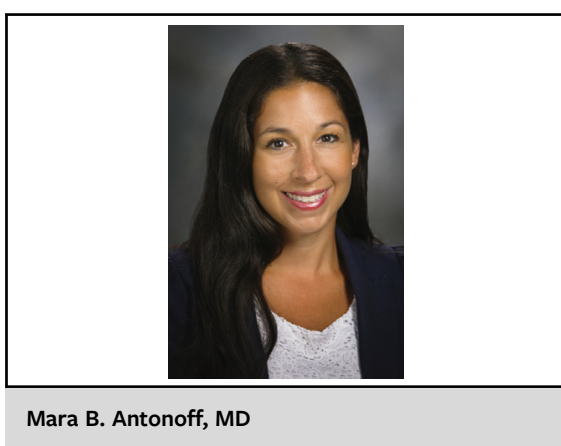

CENTRAL MESSAGE

Drs Lam and Farber explain genetic engineering strategies against viral disease, highlighting the importance of familiarity with medical knowledge across a breadth of specialties and time

authors have periods.

framed this

innovative

investigatory

work in a manner that is digestible and comprehensible to the cardiothoracic community at large.

Along with providing an overview of strategies and mechanisms for providing patients with protective antibodies, Drs Lam and Farber succinctly describe the recent study by Moffett and colleagues ${ }^{2}$ published in Science Immunology. Lam and Farber do an excellent job outlining the key elements of the experimental design, its inherent limitations, and future directions. Most importantly, they discuss the relevance of these findings to patient populations treated by the cardiothoracic surgical workforce, including transplant recipients, as well as patients with 